\title{
Economic Valuation of Power and Energy Losses in Distribution Networks
}

\author{
Smajo Bisanovic*, Mersiha Samardzic**, Damir Aganovic* \\ * Public Enterprise Elektroprivreda of Bosnia and Herzegovina d.d. - Sarajevo, Bosnia and Herzegovina \\ ** Faculty of Electrical Engineering, University of Sarajevo, Bosnia and Herzegovina
}

\begin{tabular}{l} 
Article Info \\
\hline Article history: \\
Received Oct 11, 2015 \\
Revised Dec 6, 2015 \\
Accepted Dec 26, 2015 \\
\hline Keyword: \\
Distribution network \\
Power and energy losses \\
Price at the network node \\
Price of energy losses
\end{tabular}

\section{Corresponding Author:}

Smajo Bisanovic,

Public Enterprise Elektroprivreda of Bosnia and Herzegovina d.d. - Sarajevo,

Vilsonovo setaliste 15,

71000 Sarajevo, Bosnia and Herzegovina.

Email: s.bisanovic@elektroprivreda.ba
Copyright (C) 2016 Institute of Advanced Engineering and Science. All rights reserved.

\section{INTRODUCTION}

Researchers' attention has been occupied by estimation of power and energy losses in distribution networks long since. The greatest efforts when it comes to estimation of power and energy losses are concentrated on energy losses assessment on a yearly basis and power losses assessment at maximum load in the network [1]. The need for power and energy losses estimation arises from the following reasons: optimization of expansion and further development of the distribution network, choice of optimal location and sizing of distributed generators and compensation devices, dynamic network reconfiguration and voltage optimization in distribution network, analysis of the network efficiency and performances, etc. In addition, in a competitive and deregulated environment the quality of losses estimation is crucial for fair competition in electricity markets. In today's market, distribution utilities, suppliers, distribution network operators, as well as consumers, expect estimation of losses with highest accuracy. Correct allocation of losses is necessary for correct allocation of corresponding costs. The losses in distribution network must be fairly allocated among all consumers and distributed generators. In recent literature, regarding losses costs allocation, several methods have been proposed, such as postage stamp [1-3], MW-mile [4], circuit based and proportional sharing [5]. Recently, there has been proposed a modified proportional sharing procedure [6] based on the allocation of entire losses to consumers disregarding the influence of distributed generators using the basic proportional sharing principle. Secondly, marginal procedures have been extensively proposed in order to send efficient economical signals to the market agents. Marginal methods require a slack bus designation and do not assign arbitrarily power losses between producers and consumers [1].

Allocation of losses costs in distribution networks is a complex problem whose importance increased in competitive market and in networks with high penetration of distributed generators [7]. Pricing 
of distribution network includes the allocation of capital and operating costs to users (consumers, generators) of the network in fair and equitable manner, taking into consideration that each user is charged for those costs only for which they are responsible. Marginal cost pricing is the most widely accepted concept for achieving this. By definition, the marginal cost of a good or service is the increase in the total cost of providing the good or service as a result of a relatively small increase in the rate of output of the good or service [7]. In order to allocate power losses in distribution networks with distributed generation, the concept of marginal loss coefficients is introduced [8-10]. These coefficients measure the change in total active power losses caused by marginal changes in consumption and/or generation of active and reactive power at each node in the distribution network.

In this paper we propose a simple methodological framework that determines prices of power and energy at each node of the distribution network, as well as the economic value of energy losses in the network elements. Given its simplicity, proposed framework can be very useful for a quick losses costs assessment, as a part of losses costs allocating procedures for network users and in other applications regarding distribution network, such as optimization of development and operation.

This paper is organized as follows. Section 2 provides the mathematical formulation of the problem. In Section 3 are presented the results from several case studies. The conclusions and point to future research are outlined in Section 4.

\section{MATHEMATICAL FORMULATION OF THE PROBLEM}

In order to present mathematical model for power and energy losses valuation in distribution networks, it is suitable to start with simple distribution network with $n$ nodes, as illustrated in Figure 1.

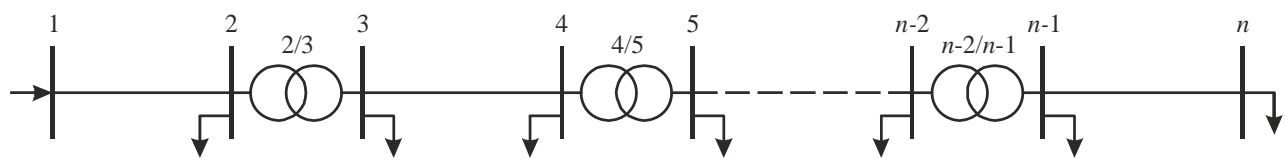

Figure 1. Simple concept of distribution network with $n$ nodes

For valuation power and energy losses according to the methodological approach that follows, it is necessary to determine economic value of $1 \mathrm{~kW}\left(\pi_{\mathrm{P}}\right)$ and $1 \mathrm{kWh}\left(\pi_{\mathrm{W}}\right)$ at each node of the distribution network $(1,2, \ldots, n)$.

\subsection{Calculation of Parameter $\pi_{\mathbf{P}}$}

Economic value of $1 \mathrm{~kW}\left(\pi_{\mathrm{P}}\right)$ at each node of the network according to Figure 1 can be determined starting from the purchase price of $1 \mathrm{~kW}$ at node $1, \pi_{\mathrm{P} 1}$, (at the network supply point) and costs for transfer power to particular node in the network. If the purchase price $\pi_{\mathrm{P} 1}$ at node 1 is known, then the economic value of power at the end of section 1-2, at node 2, can be determined as follows:

$$
\pi_{\mathrm{P} 2}=\pi_{\mathrm{P} 1}+\Delta \pi_{\mathrm{P} 12}
$$

where $\Delta \pi_{\mathrm{P} 12}$ is increment of the economic value of power that is transmitted from node 1 to node 2 .

Increment $\Delta \pi_{\mathrm{P} 12}$ represents the annual costs related to amortization, maintenance and other fixed costs for section $1-2, \Delta \pi_{\mathrm{P} 12}^{i}$, plus costs for power losses in this section, $\Delta \pi_{\mathrm{P} 12}^{p}$. The annual costs $\Delta \pi_{\mathrm{P} 12}^{i}$ for section 1-2 are given as follows:

$$
\Delta \pi_{\mathrm{P} 12}^{i}=\frac{\alpha_{12} \mathrm{I}_{12}}{100 \mathrm{P}_{2}}
$$

where:

- $\alpha_{12}$ is fixed annual costs factor for section $1-2$, [\%];

- $\mathrm{I}_{12}$ is purchase value of the equipment for section 1-2 (capital costs), [\$];

- $\mathrm{P}_{2}$ is power transferred to node 2 at maximum load, [kW]. 
The costs related to power losses in section 1-2 are given as follows:

$$
\Delta \pi_{\mathrm{P} 12}^{p}=\frac{\Delta \mathrm{P}_{12} \pi_{\mathrm{P} 1}}{\mathrm{P}_{2}}
$$

where $\Delta \mathrm{P}_{12}$ is power losses in section $1-2$ at maximum load, [kW].

According to equations (2) and (3), equation (1) obtains the following form:

$$
\pi_{\mathrm{P} 2}=\pi_{\mathrm{P} 1}+\frac{\alpha_{12} \mathrm{I}_{12}}{100 \mathrm{P}_{2}}+\frac{\Delta \mathrm{P}_{12} \pi_{\mathrm{P} 1}}{\mathrm{P}_{2}}
$$

Each $\mathrm{kW}$ which is transferred to node 2 is charged at the cost of transmission to that node. Economic value of $1 \mathrm{~kW}$ at the end of the following section, at node 3, is found in a completely analogous way.

In the general case, for the section $(n-1)-n$, or for node $n$, it can be written:

$$
\begin{aligned}
& \pi_{\mathrm{P} n}=\pi_{\mathrm{P}(n-1)}+\frac{\alpha_{(n-1) n} \mathrm{I}_{(n-1) n}}{100 \mathrm{P}_{n}}+\frac{\Delta \mathrm{P}_{(n-1) n} \pi_{\mathrm{P}(n-1)}}{\mathrm{P}_{n}} \\
& \pi_{\mathrm{P} n}=\pi_{\mathrm{P} 1}+\sum_{k=2}^{n} \frac{\alpha_{(k-1) k} \mathrm{I}_{(k-1) k}}{100 \mathrm{P}_{k}}+\sum_{k=2}^{n} \frac{\Delta \mathrm{P}_{(k-1) k} \pi_{\mathrm{P}(k-1)}}{\mathrm{P}_{k}}
\end{aligned}
$$

where:

- $\alpha_{(k-1) k}$ is fixed annual costs factor for section $(k-1)-k$, [\%];

- $\mathrm{I}_{(k-1) k}$ is purchase value of the equipment for the section $(k-1)-k$ (capital costs), [\$];

- $\mathrm{P}_{k}$ is power transferred to node $k$ at maximum load, [kW];

- $\pi_{\mathrm{P}(k-1)}$ is economic value of $1 \mathrm{~kW}$ at node $(k-1),[\$ / \mathrm{kW}]$.

\subsection{Calculation of Parameter $\pi_{\mathrm{W}}$}

Economic value of $1 \mathrm{kWh}\left(\pi_{\mathrm{W}}\right)$ at each node of the network according to Figure 1 can be determined starting from the purchase price of $1 \mathrm{kWh}$ at the node $1, \pi_{\mathrm{W} 1}$, (at the network supply point) and costs of energy losses in appropriate sections of the distribution network. As the costs associated with the amortization, maintenance and other fixed costs as well as power losses related to the economic value of 1 $\mathrm{kW}$ at each node in the distribution network, the economic value of $1 \mathrm{kWh}$ of electrical energy at the appropriate nodes will affect only energy losses. The initial assumption in determining parameter $\pi_{\mathrm{Wn}}$ is the existence of equality between the economic value of the energy accepted at the beginning of the one section and the economic value of energy delivered in the same period at the end of this section. If the accepted amount of energy during this period at the beginning of section 1-2 is $\mathrm{W}_{1}$, with the price $\pi_{\mathrm{W} 1}$, the economic value of $1 \mathrm{kWh}$ at the end of this section, where the delivered energy is $W_{2}$, with the price $\pi_{\mathrm{W} 2}$, can be determined according to the equation:

$$
\pi_{\mathrm{W} 1} \mathrm{~W}_{1}=\pi_{\mathrm{W} 2} \mathrm{~W}_{2}
$$

Since

$$
\mathrm{W}_{2}=\mathrm{W}_{1}-\Delta \mathrm{W}_{12}
$$

where $\Delta \mathrm{W}_{12}$ is energy losses in section $1-2$, from equation (7) follows:

$$
\pi_{\mathrm{W} 2}=\pi_{\mathrm{W} 1} \frac{\mathrm{W}_{1}}{\mathrm{~W}_{1}-\Delta \mathrm{W}_{12}}
$$


Economic value of $1 \mathrm{kWh}$ at the end of the following section, the transformation $2 / 3$, at node 3 , is found in a completely analogous way:

$$
\pi_{\mathrm{W} 3}=\pi_{\mathrm{W} 2} \frac{\mathrm{W}_{2}}{\mathrm{~W}_{2}-\Delta \mathrm{W}_{23}}=\pi_{\mathrm{W} 1} \frac{\mathrm{W}_{1}}{\mathrm{~W}_{1}-\Delta \mathrm{W}_{12}} \frac{\mathrm{W}_{2}}{\mathrm{~W}_{2}-\Delta \mathrm{W}_{23}}
$$

In the general case, for node $n$, it can be written:

$$
\pi_{\mathrm{W} n}=\pi_{\mathrm{W} 1} \prod_{k=2}^{n} \frac{\mathrm{W}_{(k-1)}}{\mathrm{W}_{(k-1)}-\Delta \mathrm{W}_{(k-1) k}}
$$

All equations for determining parameters $\pi_{\mathrm{P}}$ and $\pi_{\mathrm{W}}$ are derived for case illustrated in Figure 1 with a directional 'transmission' of energy containing lines and transformers, and which are connected to each other from the higher to lower voltages. However, these equations can be used for appropriate voltage level, considering that all their variables are related with this voltage level (variable costs, power, energy, losses). In this way it is possible to determine the economic value of $1 \mathrm{~kW}$ and $1 \mathrm{kWh}$ at each node of the distribution network.

\subsection{Calculation of Parameters $\pi_{\mathrm{P}}$ and $\pi_{\mathrm{W}}$ in Radial Network with more Main Sections}

Model presented by equations (6) and (11) can be generalized for any number of main sections (one main section is illustrated by simplified scheme in Figure 1 to determine the value of the parameters $\pi_{\mathrm{P}}$ and $\pi_{\mathrm{W}}$ at each node of the network). The simplified scheme with $\mathrm{N}$ main sections is illustrated in Figure 2. The parameters $\pi_{\mathrm{P}}$ and $\pi_{\mathrm{W}}$ for any section $(j=1, \ldots, \mathrm{N})$ can be determined as follows:

$$
\begin{aligned}
& \pi_{\mathrm{P} n}^{(j)}=\pi_{\mathrm{P} 1}+\sum_{k=2}^{n} \frac{\alpha_{(k-1) k}^{(j)} \mathrm{I}_{(k-1) k}^{(j)}}{100 \mathrm{P}_{k}^{(j)}}+\sum_{k=2}^{n} \frac{\Delta \mathrm{P}_{(k-1) k}^{(j)} \pi_{\mathrm{P}(k-1)}^{(j)}}{\mathrm{P}_{k}^{(j)}}(j=1, \ldots, N) \\
& \pi_{\mathrm{W} n}^{(j)}=\pi_{\mathrm{W} 1} \prod_{k=2}^{n} \frac{\mathrm{W}_{(k-1)}^{(j)}}{\mathrm{W}_{(k-1)}^{(j)}-\Delta \mathrm{W}_{(k-1) k}^{(j)}}(j=1, \ldots, N)
\end{aligned}
$$

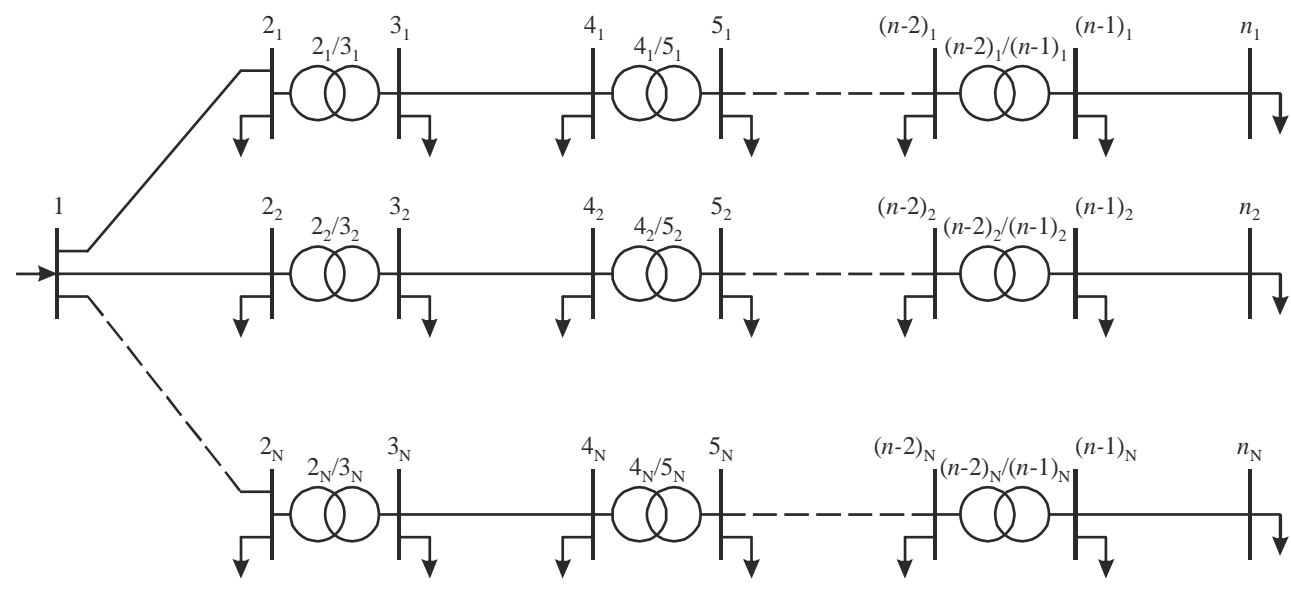

Figure 2. Simple concept of distribution network with $\mathrm{N}$ main sections

\subsection{Economic Value of Losses}

The economic value of power $\pi_{\mathrm{P}}$ and energy $\pi_{\mathrm{W}}$ at each node of the network can be used to determine the economic value of the losses. If the amount of power losses at the time of maximum load in 
network for section $(k-1)-k$ is $\Delta \mathrm{P}_{(k-1)-k}$, and the amount of energy losses in this section in the considered period is $\Delta \mathrm{W}_{(k-1)-k}$, then costs of the losses in this section can be determined as follows:

$$
\mathrm{C}_{(k-1) k}^{\text {loss }}=\Delta \mathrm{P}_{(k-1) k} \pi_{\mathrm{P}(k-1)}+\Delta \mathrm{W}_{(k-1) k} \pi_{\mathrm{W}(k-1)}
$$

The amount of energy losses can be expressed by power losses at the time of maximum load and equivalent time duration of the peak losses:

$$
\Delta \mathrm{W}_{(k-1) k}=\Delta \mathrm{P}_{(k-1) k} \tau_{(k-1) k}
$$

where $\tau_{(k-1)-k}$ is equivalent time duration of the peak losses, then equation (14) can be written in the form:

$$
\mathrm{C}_{(k-1) k}^{\text {loss }}=\Delta \mathrm{P}_{(k-1) k} \pi_{\mathrm{P}(k-1)}+\Delta \mathrm{P}_{(k-1) k} \tau_{(k-1) k} \pi_{\mathrm{W}(k-1)}
$$

Economic value of the energy losses can be found from the equation (16) as follows:

$$
c_{(k-1) k}=\frac{\mathrm{C}_{(k-1) k}^{\text {loss }}}{\Delta \mathrm{W}_{(k-1) k}}=\frac{\pi_{\mathrm{P}(k-1)}}{\tau_{(k-1) k}}+\pi_{\mathrm{W}(k-1)}
$$

and it depends on the equivalent time duration of the peak losses $\tau$ and parameters $\pi_{\mathrm{P}}$ and $\pi_{\mathrm{W}}$. For longer time $\tau$ (for which the load diagram is more uniform), economic value of the energy losses in the appropriate section is lower. Equation (17) can be used for the actual tariff system. Network losses can be valorized by actual tariff system in a way that parameter $\pi_{\mathrm{p}}$ is tariff element for power and parameter $\pi_{\mathrm{W}}$ is tariff element for energy. The main difficulty in application of equation (17) is the unknowing the load diagram of network elements. If the load diagram is not accessible, unlike values of delivered energy and maximum power, then equivalent time duration of the peak losses $\tau$ can be calculated according to empiric relation, for example:

$$
\tau=0,17 T_{\mathrm{m}}+0,83 \frac{T_{\mathrm{m}}^{2}}{T}
$$

\section{NUMERICAL RESULTS}

The proposed mathematical model was successfully tested on three distribution networks with simple configurations and in this section results are presented. In all test cases the annual costs related to amortization, maintenance and other fixed costs of the network elements are neglected.

\section{Test case 1.}

Data for test case 1 is given in Figure 3. According to mathematical model given in Section 2, the values of parameters $\pi_{\mathrm{P}}$ and $\pi_{\mathrm{W}}$ for each node, as well as economic value of energy losses for each network section, are given in Table 1 . Parameters for node 1 are: $\pi_{\mathrm{P} 1}=0,10627 \$ / \mathrm{kW}$ and $\pi_{\mathrm{W} 1}=0,05983 \$ / \mathrm{kWh}$.

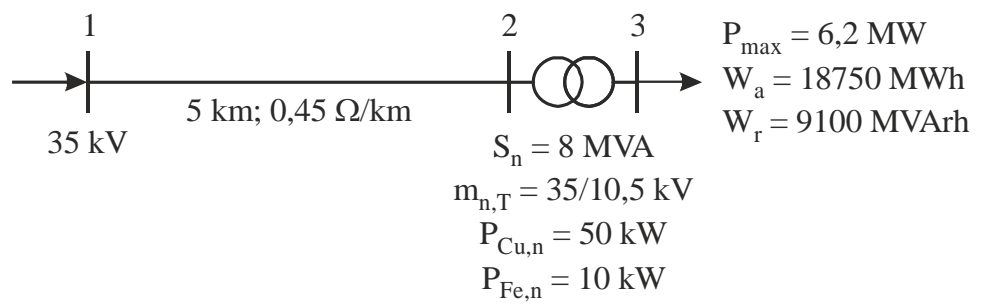

Figure 3. Simple distribution network for test case 1 
Table 1. Results for test case 1

\begin{tabular}{ccccccccccc}
\hline node & node & $\Delta \mathrm{P}_{(\mathrm{k}-1) \mathrm{k}}$ & $\mathrm{P} k$ & $\mathrm{~T}_{\mathrm{m}, \mathrm{k}-1) \mathrm{k}}$ & $\tau_{(\mathrm{k}-1) \mathrm{k}}$ & $\Delta \mathrm{W}_{(\mathrm{k}-1) \mathrm{k}}$ & $\mathrm{W}_{\mathrm{k}}$ & $\pi_{\mathrm{Pk}}$ & $\pi_{\mathrm{Wk}}$ & $\mathrm{C}_{(\mathrm{k}-1) \mathrm{k}}$ \\
$\mathrm{k}-1$ & $\mathrm{k}$ & $\mathrm{kW}$ & $\mathrm{kW}$ & $\mathrm{h}$ & $\mathrm{h}$ & $\mathrm{kWh}$ & $\mathrm{kWh}$ & $\$ / \mathrm{kW}$ & $\$ / \mathrm{kWh}$ & $\$ / \mathrm{kWh}$ \\
\hline 1 & 2 & 87,17 & $6.332,46$ & $3.024,2$ & $1.380,7$ & $120.345,40$ & $18.886 .323,6$ & 0,10773 & 0,06021 & 0,05991 \\
2 & 3 & 45,29 & $6.200,00$ & $3.024,2$ & $1.380,7$ & $136.323,56$ & $18.750 .000,0$ & 0,10852 & 0,06065 & 0,06029 \\
\hline
\end{tabular}

\section{Test case 2 .}

The second test case is illustrated in Figure 4. Parameters for node 1 are: $\pi_{\mathrm{P} 1}=0,11439 \$ / \mathrm{kW}$ and $\pi_{\mathrm{W} 1}=0,07126 \$ / \mathrm{kWh}$. The values of parameters $\pi_{\mathrm{P}}$ and $\pi_{\mathrm{W}}$ for each node, as well as economic value of energy losses for each network section, are given in Table 2. Data needed for the calculation is specified in Figure 4.

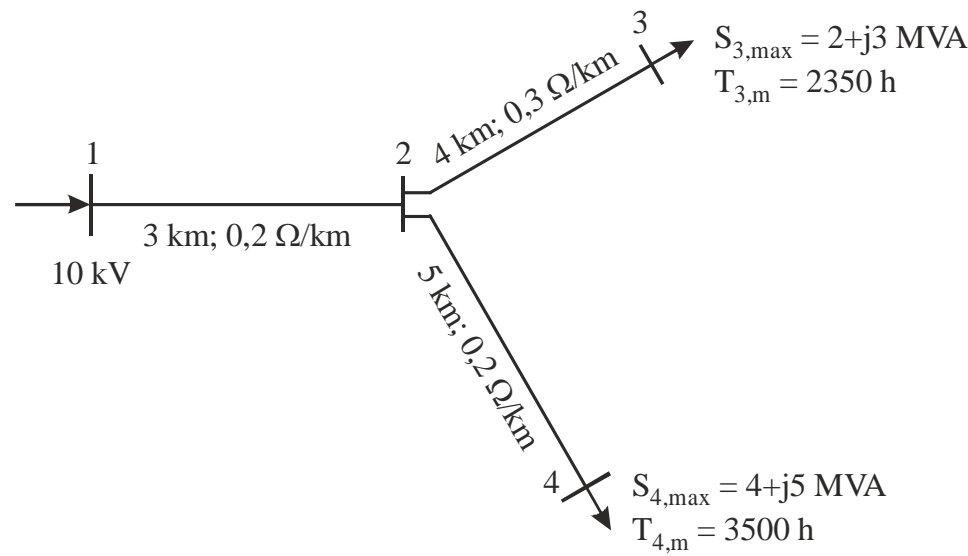

Figure 4. Simple distribution network for test case 2

Table 2. Results for test case 2

\begin{tabular}{ccccccccccc}
\hline node & node & $\Delta \mathrm{P}_{(\mathrm{k}-1) \mathrm{k}}$ & $\mathrm{P}_{\mathrm{k}}$ & $\mathrm{T}_{\mathrm{m},(\mathrm{k}-1) \mathrm{k}}$ & $\tau_{(\mathrm{k}-1) \mathrm{k}}$ & $\Delta \mathrm{W}_{(\mathrm{k}-1) \mathrm{k}}$ & $\mathrm{W}_{\mathrm{k}}$ & $\pi_{\mathrm{Pk}}$ & $\pi_{\mathrm{Wk}}$ & $\mathrm{C}_{(\mathrm{k}-1) \mathrm{k}}$ \\
$\mathrm{k}-1$ & $\mathrm{k}$ & $\mathrm{kW}$ & $\mathrm{kW}$ & $\mathrm{h}$ & $\mathrm{h}$ & $\mathrm{kWh}$ & $\mathrm{kWh}$ & $\$ / \mathrm{kW}$ & $\$ / \mathrm{kWh}$ & $\$ / \mathrm{kWh}$ \\
\hline 1 & 2 & 48,98 & $6.046,21$ & $2.450,0$ & 985,2 & $48.256,57$ & $41.242 .518,2$ & 0,11532 & 0,07134 & 0,07138 \\
2 & 3 & 12,74 & $2.000,00$ & $2.350,0$ & 922,8 & $11.755,84$ & $11.037 .600,0$ & 0,11605 & 0,07142 & 0,07147 \\
2 & 4 & 33,47 & $4.000,00$ & $3.500,0$ & $1.755,7$ & $58.762,39$ & $30.134 .400,0$ & 0,11702 & 0,07148 & 0,07141 \\
\hline
\end{tabular}

\section{Test case 3 .}

The third test case is illustrated in Figure 5. Parameters for node 1 are: $\pi_{\mathrm{P} 1}=0,12437 \$ / \mathrm{kW}$ and $\pi_{\mathrm{W} 1}$ $=0,09351 \$ / \mathrm{kWh}$. The values of parameters $\pi_{\mathrm{P}}$ and $\pi_{\mathrm{W}}$ for each node, as well as economic value of energy losses for each network section, are given in Table 3. Data needed for the calculation is specified in Figure 5. 


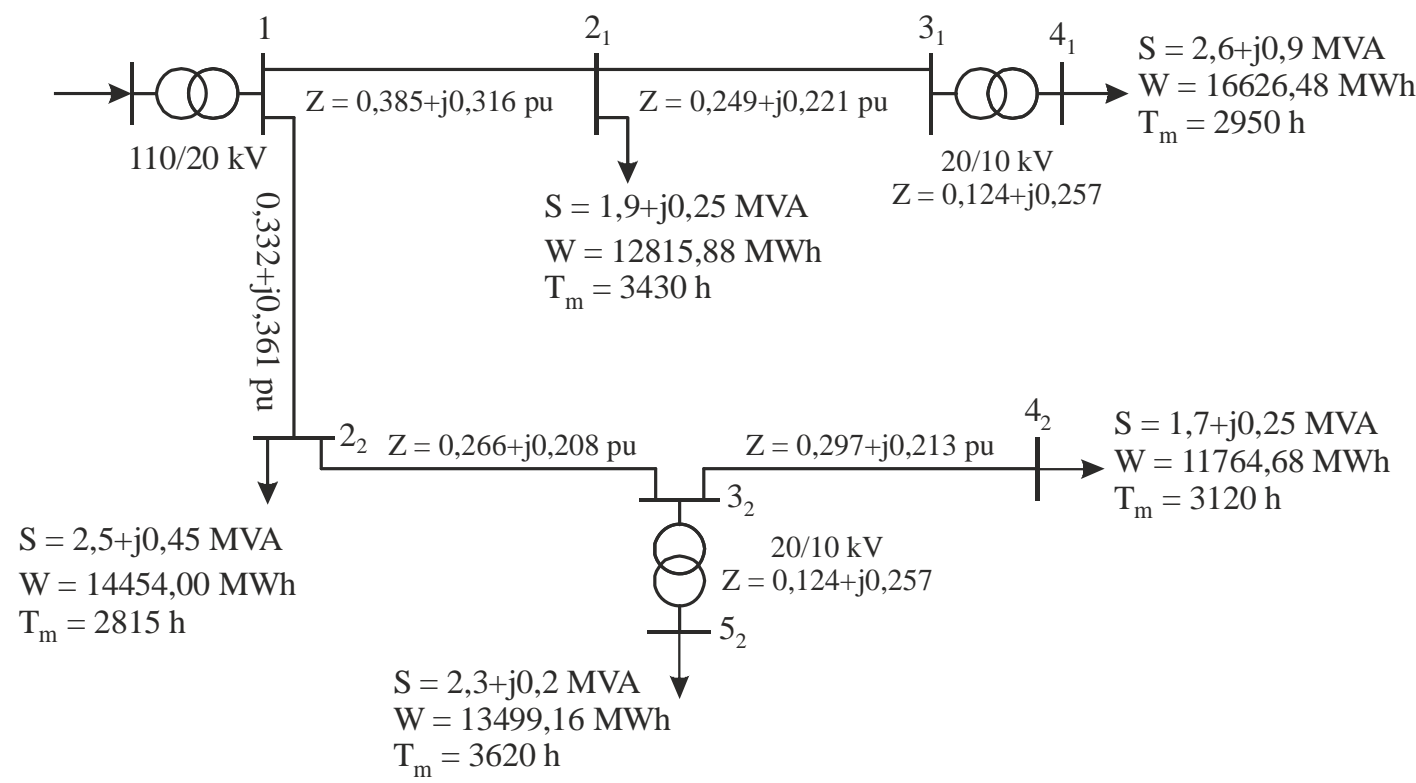

Figure 5. Simple distribution network for test case 3

Table 3. Results for test case 3

\begin{tabular}{ccccccccccc}
\hline node & node & $\Delta_{(\mathrm{k}-1) \mathrm{k}}$ & $\mathrm{P}_{\mathrm{k}}$ & $\mathrm{T}_{\mathrm{m},(\mathrm{k}-1) \mathrm{k}}$ & $\tau_{(\mathrm{k}-1) \mathrm{k}}$ & $\Delta \mathrm{W}_{(\mathrm{k}-1) \mathrm{k}}$ & $\mathrm{W}_{\mathrm{k}}$ & $\pi_{\mathrm{Pk}}$ & $\pi_{\mathrm{Wk}}$ & $\mathrm{C}_{(\mathrm{k}-1) \mathrm{k}}$ \\
$\mathrm{k}-1$ & $\mathrm{k}$ & $\mathrm{kW}$ & $\mathrm{kW}$ & $\mathrm{h}$ & $\mathrm{h}$ & $\mathrm{kWh}$ & $\mathrm{kWh}$ & $\$ / \mathrm{kW}$ & $\$ / \mathrm{kWh}$ & $\$ / \mathrm{kWh}$ \\
\hline 1 & $2_{1}$ & 83,02 & $4.529,35$ & $3.152,7$ & $1.477,7$ & $122.680,06$ & $16.665 .399,6$ & 0,12665 & 0,09390 & 0,09359 \\
$2_{1}$ & $3_{1}$ & 19,24 & $2.610,11$ & $2.950,0$ & $1.326,1$ & $25.513,24$ & $16.639 .886,4$ & 0,12758 & 0,09404 & 0,09399 \\
$3_{1}$ & $4_{1}$ & 10,11 & $2.600,00$ & $2.950,0$ & $1.326,1$ & $13.406,39$ & $16.626 .480,0$ & 0,12808 & 0,09412 & 0,09414 \\
1 & $2_{2}$ & 142,00 & $6.633,71$ & $3.192,2$ & $1.508,1$ & $214.156,21$ & $25.500 .307,7$ & 0,12703 & 0,09401 & 0,09359 \\
$2_{2}$ & $3_{2}$ & 47,04 & $4.086,67$ & $3.420,3$ & $1.689,8$ & $79.489,37$ & $25.420 .818,3$ & 0,12849 & 0,09469 & 0,09409 \\
$3_{2}$ & $4_{2}$ & 10,41 & $1.700,00$ & $3.150,0$ & $1.475,6$ & $15.361,47$ & $11.764 .680,0$ & 0,12928 & 0,09482 & 0,09478 \\
$3_{2}$ & $5_{2}$ & 76,26 & $2.300,00$ & $3.620,0$ & $1.857,0$ & $141.616,87$ & $13.499 .160,0$ & 0,13275 & 0,09569 & 0,09476 \\
\hline
\end{tabular}

\section{CONCLUSIONS AND FUTURE RESEARCH}

This paper proposed a simple methodological framework that determines prices of power and energy at each node of the distribution network, as well as the economic value of energy losses in the network elements. Given its simplicity, proposed framework can be very useful for a quick losses costs assessment, as a part of losses costs allocation procedures for network users. It is transparent and could be practical for implementation. Applications on the test cases presented in Section 3 put these objectives into perspective. In order to ensure the application of the model on real-life distribution network with distributed generation, presented methodological framework should be modified, which is future research challenge. Economically efficient network prices should be computed by considering the marginal impact of each user on network costs: loads and generators. The type of user (load or generator) and the pattern of network use are key determinants of individual user's impact on the network costs.

\section{REFERENCES}

[1] P.M. de Oliveira-de Jesus, et al., "Cost loss allocation in distribution networks with high penetration of distributed renewable generation - a comparative study", in Proceedings of the International Conference on Renewable Energies and Power, Zaragoza, 2005.

[2] D. Shirmohammadi, and P.R. Gribik, "Evaluation of network capacity use for wheeling transactions", IEEE Transactions on Power Systems, vol. 4, no. 4, pp. 1405-1413, 1989. 
[3] H.H. Happ, "Cost of wheeling methodologies", IEEE Transactions on Power Systems, vol. 9, no. 1, pp. 147-155, 1994.

[4] A.J. Conejo, et al., "Z-bus loss allocation", IEEE Transactions Power Systems, vol. 16, no. 1, pp. 105-110, 2001.

[5] J.W. Bialek, "Tracing the flow of electricity", in IEE Proceedings Generation, Transmission and Distribution, vol. 143, pp. 310-320, 1996.

[6] P.M. Costa, and M. Matos, "Loss allocation in distribution network with embedded generation", IEEE Transactions on Power Systems, vol. 19, no. 1, pp. 384-389, 2004.

[7] K.A. Papadogiannis, et al., "Cost allocation of losses in autonomous power systems with high penetration of RES", WSEAS Transactions on power systems, vol. 4, no. 6, pp. 210-220, 2009.

[8] J. Mutale, et al., "Allocation of losses in distribution systems with embedded generation", in IEE Proceedings Generation, Transmission and Distribution, vol. 147, no. 1, pp. 7-14, 2000.

[9] P.M. De Oliveira-de Jesus, and M.T. Ponce de Leao, "Cost loss allocation in distribution networks with embedded generation: A fuzzy approach", in Proceedings of IEE MedPower 2004, Limassol, 2004.

[10] J.M. Vignolo, and P.M. Sotkiewicz, "Allocation of loss costs in distribution networks: the nodal factor pricing method", International Journal of Power Systems, vol. 10, no. 10, pp. 1-10, 2004.

\section{BIOGRAPHIES OF AUTHORS}

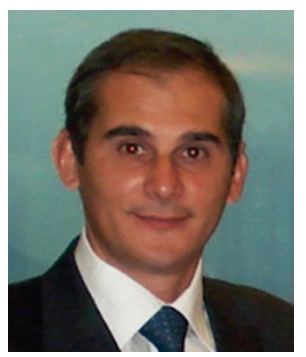

Smajo Bisanovic received the degree of Electrical Engineer in 1991, MSc degree in 1994 and $\mathrm{PhD}$ degree in 2009 from the Faculty of Electrical Engineering, University of Sarajevo, Bosnia and Herzegovina. He is associate professor at the Faculty of Electrical Engineering, University of Sarajevo, Bosnia and Herzegovina. His areas of interest include operation, planning and economics of power systems and application of reliability theory to power systems.

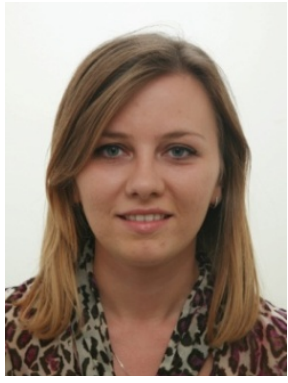

Mersiha Samardzic received a BSc degree in power electrical engineering for the Faculty of Electrical Engineering, University of Sarajevo, Bosnia and Herzegovina in 2014. She is now pursuing her MSc degree in the same Faculty. Her research interests include computer simulations and design analysis applied to power systems.

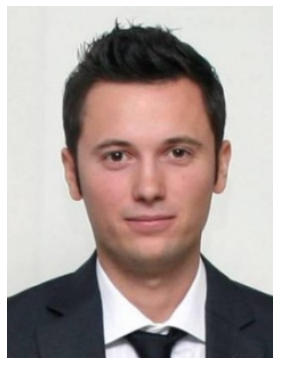

Damir Aganovic is received a MSc degree in power electrical engineering from the Faculty of Electrical Engineering, University of Sarajevo, Bosnia and Herzegovina in 2010. He is currently pursuing his $\mathrm{PhD}$ degree in the same field at the same University. He is an Expert associate for Power System Operation Management at Public Enterprise Elektroprivreda of Bosnia and Herzegovina. His areas of interest include operation and planning of power systems. 